\title{
Covid-19: What's the current advice for UK doctors?
}

\author{
Abi Rimmer
}

The BMJ

\section{I haven't been fit tested for the correct masks (FFP3)? Can I be asked to go into a room with a patient with suspected or confirmed covid-19?}

UK employers have a legal obligation under the Health and Safety at Work Act 1974 to protect staff from harm. And the Control of Substances Hazardous to Health Regulations place a duty to carry out individual risk assessments to identify hazards, quantify risks, and put suitable controls in place, says Steven Nimmo, editor of the Occupational Medicine Journal. "If the risk assessment establishes that personal protective equipment (PPE) is required then your employer must provide it, properly fit it, and provide suitable instruction and training in its use," he says.

Public Health England's guidance says that clinicians preparing to assess a patient with suspected covid-19 must wear PPE, which as a minimum should be a correctly fitted FFP3 respirator, gown, gloves, and eye protection. ${ }^{1}$ Doctors seeing patients with confirmed covid-19 must wear full PPE, including a FFP3 respirator, disposable eye protection, and preferably a visor, a long sleeved disposable gown, and gloves, PHE says. For symptomatic, unconfirmed patients, doctors should wear a fluid resistant surgical mask, gloves, apron and eye protection if there is a risk of splashing into the eyes, PHE recommends. ${ }^{2}$

\section{I'm pregnant or immunosuppressed. What rights do I have to protect myself from infection at work?}

\footnotetext{
"Pregnant women and children are not at high risk," Nimmo says. "But the above legal obligations still apply.

Immunosuppressed people may well be at increased risk, depending on the reason for the immunosuppression, and drug type and dosage, and so on. The risk assessment should take this into account. The advice may well be to avoid exposure to covid-19, which could mean redeployment to a non-frontline role."
}

\section{Is there specific advice for other high risk chronic diseases?}

People with chronic heart and lung disease have a higher risk of complications and higher mortality than the general population. "As a general rule they should not be exposed to infection, and, again, redeployment to a non-frontline role may be appropriate following the risk assessment," says Nimmo.

I'm concerned that I may have to work in unsafe conditions. How can I protect myself?

The GMC acknowledges that doctors may be anxious about context not being taken into account when concerns are raised about their actions in very challenging circumstances. ${ }^{3}$ In a statement it said, "Where a concern is raised about a registered professional, it will always be considered on the specific facts of the case, taking into account the factors relevant to the environment in which the professional is working. We would also take account of any relevant information about resources, guidelines, or protocols in place at the time."

\section{How can I decline if I am asked to work beyond my clinical competence?}

The GMC says that if the epidemic worsens it is likely that doctors will have to work outside their normal field of practice. "When deciding the safest and best course of action in the circumstances, doctors should consider factors including what is within their knowledge and skills; the protection and needs of all patients they have a responsibility towards; and minimising the risk of transmission and protecting their own health," a GMC spokesperson said.

Matthew Lee, director of professional services at the Medical Defence Union, said that any doctor faced with clinical duties outside their clinical competence should "explain their concerns clearly to someone with responsibility for providing the service to determine the safest way to proceed." If they have done so and still feel uncomfortable, their medical defence organisations can advise them further, he said.

\section{I'm out of practice and thinking about coming back to work. What do I need to do?}

Government powers allow the GMC to grant temporary registration to certain groups in emergency cases. If this happens, doctors won't need to go through the registration process themselves, as it will be done automatically for them The GMC says that it would not charge doctors for this temporary registration, and it does not envisage that they would 
be subject to revalidation. The first group to be registered would be fully qualified and experienced doctors of good standing who have recently relinquished their registration or licence to practise.

\section{If I return, what will I be asked to do?}

The government has not officially asked retired doctors to return to work. But England's chief medical officer, Chris Whitty, has said that older doctors and those with pre-existing health conditions could be put into "non-patient facing roles that may still be clinical-for example, NHS 111."

\section{If I come out of retirement, will I be covered by NHS indemnity?}

Rob Hendry, medical director at the Medical Protection Society (MPS), says, "The assumption is that 'emergency indemnity' to enable some retired doctors to practise would be state backed, as it would be NHS contracted work, specifically to support the government's plan to manage covid-19. If those individuals who are former Medical Protection members wished to reactivate their membership to access supplementary non-claims benefits for a limited period, they would be welcomed.

"We recognise the potential for an emergency situation and will take all possible steps to ensure that our members can treat patients, safe in the knowledge that their membership will provide them with support and assistance should it be required."

\section{I'm a trainee. Will I have to extend my training if helping out with the outbreak stops me meeting my training requirements?}

A spokesperson for Health Education England said that it is doing its utmost to reduce the impact on trainees of any move in placement or change in duties. The exceptional nature of current circumstances will be taken into account in assessment of progress against the curriculum at the next progression panel, HEE said.

\section{How do I handle patients' requests for extra medication?}

While there are currently no reported medicine shortages as a result of covid-19, general practices may face requests from patients for extra medication to stockpile "just in case," says Hendry. MPS advises GPs to resist pressure to overprescribe and to stick to existing policy on repeat prescribing unless they receive official advice stating otherwise.

\section{I am increasingly having to see patients remotely. Does this affect my indemnity?}

In making the decision to consult and advise patients remotely, doctors must balance the risks and benefits and be satisfied that they can adequately clinically assess the patient remotely, says Hendry. MPS advises doctors to make a record of the reasoning behind any decisions made and the information they give to patients in case they need to explain the approach they've taken later on.

\section{As a trainee, will I be supervised if I have to work in unfamiliar environments?}

An HEE spokesperson said that trainees would be expected to work in different clinical areas or for a different provider only in "truly exceptional circumstances." Where this is required, the spokesperson said, it will be in the short to medium term, and arrangements will be in place to ensure that trainees work within the limits and are fully supervised.

In a letter sent to NHS trusts and general practices, HEE said that organisations should have plans in place to ensure that there is clear accountability for trainees, and their supervision, while they are caring for patients in unfamiliar environments.

It also said that organisations should ensure that, in these instances, trainees are not "unreasonably burdened with educationally unproductive tasks" that might stop them from developing their required competencies.

\section{I'm about to graduate from medical school and would really like to help. Can I start work before August?}

HEE is in discussion with the GMC and medical schools to see how medical students could safely help if needed.

This information is accurate as at 10 March 2020.

Correction: We initially published the wrong response to the question "If I come out of retirement, will I be covered by NHS indemnity?" We replaced it with the correct response on 11 March.

Clarification: Since we published this story on 10 March Public Health England has changed its guidance on what PPE doctors and other staff should wear when assessing or treating patients with suspected covid-19. On 18 March PHE issued new guidance saying that, as a minimum, staff should wear a fluid resistant surgical mask, single use disposable apron, gloves, and eye protection if blood and or body fluid contamination of the eyes or face is anticipated. If a patient undergoes an aerosol generating procedure, staff should wear an FFP3 respirator, a long sleeved, disposable, fluid repellent gown, gloves, and eye protection. ${ }^{5}$

1 Public Health England. Covid-19: investigation and initial clinical management of possible cases. Mar 2020. https://www.gov.uk/government/publications/wuhan-novel-coronavirusinitial-investigation-of-possible-cases/investigation-and-initial-clinical-management-ofpossible-cases-of-wuhan-novel-coronavirus-wn-cov-infection.

2 Public Health England. Covid-19: infection prevention and control guidance. Mar 2020. https://www.gov.uk/government/publications/wuhan-novel-coronavirus-infection-preventionand-control/wuhan-novel-coronavirus-wn-cov-infection-prevention-and-control-guidance.

3 General Medical Council. How we will continue to regulate in light of novel coronavirus (covid-19). Mar 2020.https://www.gmc-uk.org/news/news-archive/how-we-will-continueto-regulate-in-light-of-novel-coronavirus.

4 Mahase E. Covid-19: $90 \%$ of cases will hit NHS over nine week period, chief medical officer warns. BMJ 2020;368:m918. 10.1136/bmj.m918 32139397

5 Public Health England. COVID-19: investigation and initial clinical management of possible cases. 18 Mar 2020. https://www.gov.uk/government/publications/wuhan-novel-coronavirusinitial-investigation-of-possible-cases/investigation-and-initial-clinical-management-ofpossible-cases-of-wuhan-novel-coronavirus-wn-cov-infection.

Published by the BMJ Publishing Group Limited. For permission to use (where not already granted under a licence) please go to http://group.bmj.com/group/rights-licensing/ permissions 